\title{
ICT and Sustainable Development
}

\author{
Lorenz M. Hilty ${ }^{1,2}$ and Magda David Hercheui ${ }^{3,4}$ \\ ${ }^{1}$ University of Zurich, Department of Informatics, Binzmuehlestr. 14, \\ CH-8050 Zurich, Switzerland \\ ${ }^{2}$ Empa, Swiss Federal Laboratories for Materials Science and Technology, Lerchenfeldstr. 5 \\ CH-9014 St.Gallen, Switzerland \\ ${ }^{3}$ Westminster Business School, 35 Marylebone Road, London, United Kingdom, NW1 5LS \\ ${ }^{4}$ London School of Economics, Houghton Street, London, United Kingdom, WC2A 2AE \\ lorenz.hilty@empa.ch, m.hercheui@lse.ac.uk
}

\begin{abstract}
We discuss various views and conceptual frameworks put forward in the discussion of ICT and sustainable development: An optimistic and a pessimistic view of ICT with regard to sustainability, the three-pillar approach to sustainable development, the three-level approach to ICT impacts, the claim of human, social and ecological compatibility of ICT and the plain use of ICT for development. We show that each of these approaches has its problems and limitations and conclude with formulating the challenges of finding an analytical approach which will effectively support decision-makers in using ICT in the service of sustainable development.
\end{abstract}

Keywords: Sustainable Development, Ethics, Technological Determinism, Life Cycle Assessment, Green ICT, Rebound Effect, ICT for Development.

\section{The Ethics of Sustainable Development and the Role of ICT}

The most-cited definition of "Sustainable Development" was given by the World Commission on Environment and Development: In order to be considered sustainable, a pattern of development has to ensure "that it meets the needs of the present without compromising the ability of future generations to meet their own needs" [1]. This definition, also known as the "Brundtland definition", combines two ethical claims:

- intragenerational justice (meeting the needs of the present) and

- intergenerational justice (not compromising the ability of future generations to meet their own needs).

Given the physical and biological limits of our planet [2], this double claim is in fact an ethical dilemma because extending the present consumption patterns of the industrialized countries to all parts of the world would put a great burden on future generations. Escaping this dilemma requires a structural change of the economy that will deeply affect today's industrial patterns of production and consumption. 
Regarding the role of ICT in the sustainability dilemma [3], there are two opposite positions:

- the optimistic view based on the belief that this structural change is already under way due to the development and world-wide diffusion of ICT;

- the pessimistic view in which ICT adds to resource consumption and pollution and reinforces unsustainable structures and behaviour.

Research in "ICT and Sustainable Development" or "Informatics and Sustainability" has the obligation to strive for a realistic view and provide decision-makers with scientifically sound answers. The growing body of research in this field has clearly shown that ICT is part of the solution and part of the problem at the same time (for a survey see [4] and [5]). It is therefore crucial to find models of ICT governance that exploit the potential of ICT for sustainable solutions while inhibiting the negative potential. This requires, in the first place, a conceptual framework of the interaction between the development of ICT and its applications and other societal developments. The following sections will provide a brief survey of the core ideas and approaches discussed in literature.

\section{The Limits of Technical Solutions to Sustainable Development}

Both views mentioned above - the optimistic and the pessimistic - suffer from the same problem: they are based on technological determinism insofar as they implicitly assume that ICT development cannot be controlled and the resulting impacts on society are a logical consequence of some "autonomous" technological development.

Technological determinism denies that the development and application of technologies are the result of human choice. In the context of ICT and "the information society" this basic assumption is particularly debilitating. As Holvast et al. [6] put it: "Such determinism reduces humankind to powerless pawns who can only accept their fate and wait to see what other people will do to help them. It is our belief that more can be done by human beings themselves than is often admitted."

The relationship between technological artifacts and the society that creates and interprets them is a complex one: Technologies interact with our perception of the world, which again influences how we use and develop technologies. In this process both symbolic and structuring aspects of technologies play a role, as Zuccato and Fischer-Hübner [7] describe: “...technology not only has a socio-cultural semantic effect (influence on social life) but also an effect on the subject's world experience (it influences the perception of the world and what the individual understands this to be)." Consequently, using technologies influences needs, values, beliefs and other social realities that provide the context for the further development and application of technologies.

From this view of technologies as being embedded in societal development, it follows that solutions to the sustainability dilemma will not be technical solutions alone. As far as technology is involved - and ICT might play a crucial role there - it can only be instrumental as part of a more comprehensive approach, being embedded in organizational or institutional frameworks or in structures of governance. 
Conceptual frameworks to structure and analyze the relationship between ICT and sustainable development like those described in the next section are always in danger of falling back into technological determinism by implicitly assuming a unidirectional view of "effects" or "impacts" of a "given" technology on society. It is sometimes necessary to reduce complexity by clipping one of two interacting things and then looking at the other. This is the typical approach underlying the various types of impact assessment, which has many advantages but should be embedded in a model of organizational learning, policy learning or governance [8].

\section{Conceptual Frameworks for ICT and Sustainable Development}

A conceptual framework for an analytical approach to the relationship between ICT and sustainable development first has to decompose the normative concept of sustainable development.

A very common idea is the so-called three-pillar or three-dimensional approach to sustainable development, decomposing the concept into an ecological, a social and an economic dimension. The role of ICT can then be analyzed along the following questions:

- Ecological dimension: What is the role of ICT in ecological (environmental) issues? How can we use ICT to increase our understanding of ecosystems and to reduce environmental burden (Environmental Informatics)? How can the environmental impact of production, use and disposal of ICT be reduced (Green ICT)?

- Social dimension: What is the role of ICT in social development? How can we use ICT to support (virtual) communities working towards the aim of sustainable development? How can social justice on a global scale be supported by ICT? How can we increase the contribution of ICT to long-term thinking and avoid short-sighted, technologically determined developments?

- Economic dimension: What is the role of ICT in the structural change of the economy from an industrial to a post-industrial mode? How can ICT contribute to a decoupling of economic growth from growth in resource consumption, to substitute virtual forms of production and consumption for energy-intensive processes, to dematerialize relevant parts of the economic system? And how can ICT help emerging economies to leapfrog into this mode without copying the unsustainable patterns of the industrial mode first?

Although this three-dimensional approach may serve as a starting point for brainstorming, it does not provide a sound basis for analysis. Firstly, we also need to decompose the role of ICT in this context, since digital ICT is an almost universal technology and application categories are more relevant than the technology as such. Secondly, multidimensional concepts of sustainable development have been criticized for being inconsistent (the "dimensions" are not at the same conceptual level, i.e. they wrongly suggest orthogonality) and for watering down the concept of sustainable development by suggesting that a depletion of ecological or social capital may be accepted in exchange for economic capital ("weak sustainability" [3]).

Conceptual frameworks for "ICT and sustainable development" that go beyond this approach are briefly discussed in the following sub-sections. None of these 
frameworks claims to provide a comprehensive solution. Rather, they may be viewed as ingredients in a more comprehensive approach that still has to be formulated.

\subsection{Three Levels of ICT Effects}

This approach focuses on applications of ICT and first asks in which way they influence the environment. The three levels cover environmental impacts ranging from the most direct effects (physical effects of using the hardware) to the most indirect effects such as the influence of ICT on economic structures and lifestyles [9]:

- "First-order effects: Includes all environmental impacts resulting from ICT hardware during the product lifecycle, covering production, use, and disposal."

- "Second-order effects: The use of ICT causes effects to other processes such as traffic or industrial production and influences their environmental impacts indirectly."

- "Third-order effects: Owing to the assumed widespread use of ICT in everyday life, economic structures and lifestyles can change, indirectly affecting the expression of first- and second-order effects."

The three-level approach is very common in research on environmental impacts of ICT, although it could in principle be generalized to effects on social systems, including the economic system. In fact, the concept of second-order effects presupposes some organizational context in which ICT is used, while third-order effects can only be assessed or explained in a societal context, including, for example, market dynamics.

During the last decade, a few methodologies have been explored to quantify ICT effects at each level.

At the first level, existing Life-Cycle Assessment (LCA) methodology has been applied to computers [10] and to communications infrastructure as well [12]. Life Cycle Inventory (LCI) databases (such as the ecoinvent database [11]) have been extended to include ICT hardware. Some of the work on first-order effects has also focused on end-of-life issues due to the environmental and health problems caused by informal recycling in developing countries [13] and the dissipative use of increasingly miniaturized devices $[14,15]$. With the "Green IT" or "Green ICT" hype starting in 2008, the energy consumed by ICT terminal devices and network infrastructures (in particular the Internet) has gained public attention. This view sometimes includes aspects of the second level, in particular when the idea of "Green Software" is introduced. Dick et al. [16] provide an excellent update on this topic in this volume.

At the second level, the methodologies used for quantification are more diverse and difficult to compare. How can we measure the implications of - for instance mobile work, knowing that mobile ICT is only one of many factors changing the mobility behaviour of people? Erdmann and Hilty [5] provide a review of studies which tried to quantify second-order effects of ICT applications in terms of energy saving potential (or $\mathrm{CO}_{2}$ reduction potential) at the macro-economic level, including rare cases in which first- and third-order effects were included. Three papers in this volume contribute to this body of knowledge. Houghton [17] gives significant examples of ICT applications which can mitigate climate change and other environmental pressures. Bunse and Vodicka [18] open the perspective for organizational aspects which are essential for using ICT to manage energy efficiency in manufacturing 
processes. Santana et al. [19] show how information systems with a Service-Oriented Architecture (SOA) can be used to support sustainable design.

The third level of ICT effects is the most difficult one to be treated quantitatively. Erdmann and Hilty [5] discuss how rebound effects can be dealt with in a scenariobased model. However, rebound-effects (based on efficiency-induced changes of demand) are not the only type of third-order effects: ICT deeply changes the way we communicate. This profound change can affect social systems at all levels, from an organization such as a company to the global society. This is the point where it is essential to abandon technological determinism and adopt a broader view, such as the theory of communicative action by the German philosopher Jürgen Habermas. This is the perspective advocated by Möller and Rolf ([20], in this volume) with their approach to IT support for sustainable development in organisations.

\subsection{Human, Social and Ecological Compatibility of ICT}

The German Informatics Society set up a working group named "Sustainable Information Society" to clarify the opportunities and risks of ICT for sustainable development one decade ago. The group produced a detailed memorandum that was published as a Fraunhofer IRB book in German with an English abstract [21] and summarized in international publications $[22,23]$.

The approach taken by the working group has two essential features. Firstly, it builds upon the tree-level approach described in the previous section by redefining the levels as follows:

1. "effects of supply": effects of the effort necessary to provide people with information and communications services, including the production of ICT hardware and software, supplying the energy and other resources to use ICT, and the end-of-life treatment of the hardware.

2. "effects of usage": effects of services provided by ICT viewed in the restricted context of the application, such as substitution or optimization effects.

3. "systemic effects": long-term effects that have to be taken into account, mainly because positive effects of usage may backfire in the economic system (rebound effects).

The working group emphasized that steps toward a sustainable information society cannot be based on technological measures alone [9]: "This is partially due to the socalled rebound effect, according to which a transition to more efficient technologies causes an expansion of activities given constant financial and time budgets. Because of this effect, technological measures alone do not cause a reduction in the use of natural resources by production and consumption."

The second feature of this approach is that it explicitly replaces the "three-pillar thinking" of weak sustainability (as discussed in the beginning of section 3) with the concept of three nested subjects of protection: the human individual as part of society, which is embedded in nature.

From these subjects of protection the working group derived three claims of compatibility: human, social and ecological compatibility. Combining this idea with the three levels of ICT effects yields nine fields of research and societal discourse that should be considered if ICT is to support sustainable development (see Figure 1). 


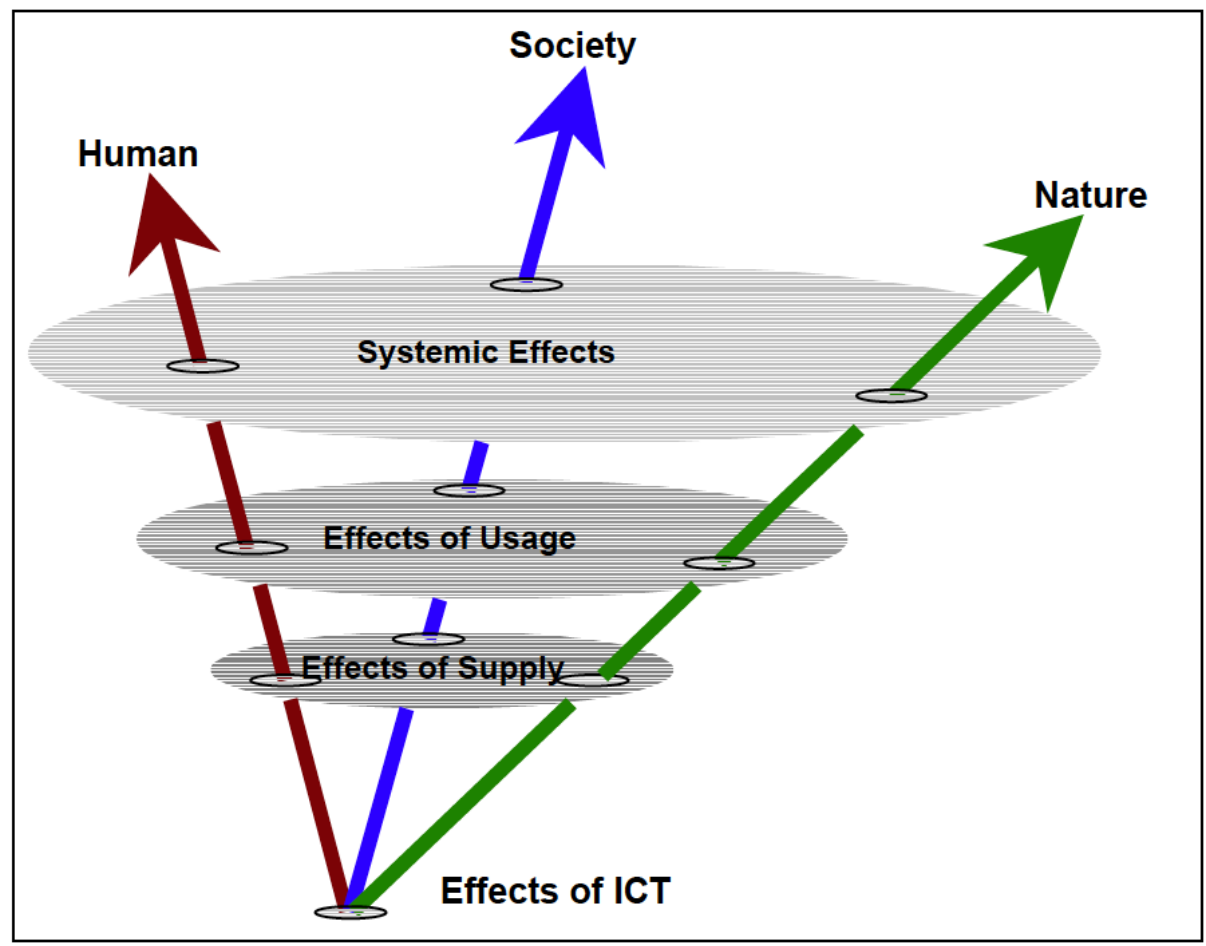

Fig. 1. The conceptual framework created by the working group "Sustainable Information Society" of the German Informatics Society in 2004 [22]

\subsection{ICT for Development}

This prominent approach differs from the two presented above by its simplicity. It ignores the sustainability dilemma we briefly introduced in Section 1 by putting the emphasis on intragenerationational justice: ICT is seen as a vehicle to empower the poor and enable development in underdeveloped regions of the world. The overuse of natural resources is implicitly expected to be reduced, rather than, increased by economic growth in poor countries.

This approach has at least some arguments working in its favour, the first of them being the statistical fact that population growth is negatively correlated with the education of young women. If it is true that ICT can successfully be applied in educating the poor, ICT would then indeed contribute to sustainable development. Secondly, there are some impressive examples of leapfrogging into the information society, most of them centered around the role of the mobile phone, which is an essential infrastructure that can be built up without waiting for other industrial infrastructures, even without centralized and stable power grids.

The issue of supplying schools in developing countries with affordable computers is treated by Streicher-Porte et al. [24], and Dobson et al. [25], showing another excellent example of ICT for development in this volume. 


\section{Conclusion: Challenges in ICT and Sustainable Development}

We have shown that analysing the relationship between ICT and sustainable development poses a number of challenges:

- finding a meaningful decomposition of the concept of sustainable development to start with,

- finding a meaningful classification of ICT interactions with aspects of sustainable development,

- finding methods to quantify effects of the ICT life cycle, of ICT applications and the way ICT changes societal structures (including the economic system), and finally,

- embedding these analyses in an organizational or political context of decisionmaking and in a societal discourse.

We hope that Track 4 "ICT and sustainable development" of the 9th Conference on Human Choice and Computers (HCC9), embedded in the 2010 IFIP World Computer Congress in Brisbane, Australia, will be a milestone in meeting these challenges.

Acknowledgments. As track programme chairs, we thank all the programme committee members for their efforts in supporting the organisation of this track. In this respect, we would especially like to acknowledge the following for their intellectual and organisational inputs: Gunilla Bradley, Katharina Bunse, Vlad Coroama, Lorenz Erdmann, Wolfgang Hofkirchner, John Houghton, Shirin Madon, Scott Matthews, Bill McIver, Therese Meier, Andreas Möller, Bernd Page, Thomas Ruddy, and Eric Williams.

\section{References}

1. World Commission on Environment and Development: Our Common Future. Oxford University Press, London (1987)

2. United Nations Millennium Ecosystem Assessment (MEA): Ecosystems and Human WellBeing: Synthesis. Island Press, Washington (2005)

3. Hilty, L.M., Ruddy, T.F.: Sustainable Development and ICT Interpreted in a Natural Science Context: the Resulting Research Questions for the Social Sciences. Information, Communication \& Society 13(1), 7-22 (2010),

http: / / dx.doi.org/10.1080/13691180903322805

4. Hilty, L.M.: Information Technology and Sustainability. In: Essays on the Relationship between ICT and Sustainability. Books on Demand, Norderstedt (2008), http: / / www . amazon.de/gp/product/3837019705/

5. Erdmann, L., Hilty, L.M.: Scenario Analysis: Exploring the Macroeconomic Impacts of Information and Communication Technologies on Greenhouse Gas Emissions. Accepted for Publication in the Journal of Industrial Ecology

6. Holvast, J., Duquenoy, P., Whitehouse, D.: The Information Society and its Consequences: Lessons from the Past. In: Berleur, J., Avgerou, C. (eds.) Perspectives and Policies on ICT in Society - An IFIP TC9 (Computers and Society) Handbook, pp. 135-152. Springer, New York (2005) 
7. Zuccato, A., Fischer-Hübner, S.: Symbolic and Structuring Effects of the Internet on Privacy. In: Berleur, J., Avgerou, C. (eds.) Perspectives and Policies on ICT in Society - An IFIP TC9 (Computers and Society) Handbook, pp. 219-237. Springer, New York (2005)

8. Ruddy, T.F., Hilty, L.M.: Impact Assessment and Policy Learning in the European Commission. Environmental Impact Assessment Review 2-3(28), 90-115 (2008), http: / /dx.doi.org/10.1016/j.eiar.2007.05.001

9. Köhler, A., Erdmann, L.: Expected Environmental Impacts of Pervasive Computing. Human and Ecological Risk Assessment 10, 831-852 (2004)

10. Williams, E.: Energy intensity of computer manufacturing: hybrid assessment combining process and economic input-output methods. Environmental Science and Technology 38(22), 6166-6174 (2004)

11. Frischknecht, R., Jungbluth, N., Althaus, H.J., et al.: The Ecoinvent Database: Overview and Methodological Framework. International Journal of Life Cycle Assessment 10, 3-9 (2005)

12. Scharnhorst, W., Hilty, L.M., Jolliet, O.: Life Cycle Assessment of Second Generation (2G) and Third Generation (3G) Mobile Phone Networks. Environment International 32, 656-675 (2006)

13. Widmer, R., Oswald-Krapf, H., Sinha-Khetriwal, D., et al.: Global Perspectives on eWaste. Environmental Impact Assessment Review 25, 436-458 (2005)

14. Hilty, L.M.: Electronic waste - an emerging risk? Environmental Impact Assessment Review 25(5), 431-435 (2005)

15. Kräuchi, P., Wäger, P., Eugster, M., Grossmann, G., Hilty, L.M.: End-of-life impacts of pervasive computing. IEEE Technology and Society Magazine 24(1), 45-53 (2005)

16. Dick, M., Naumann, S., Kuhn, N.: A Model and Selected Instances of Green and Sustainable Software. In: Berleur, J., Hercheui, M., Hilty, L.M. (eds.) HCC9/CIP 2010. IFIP AICT, vol. 328, pp. 248-259. Springer, Heidelberg (2010)

17. Houghton, J.W.: ICT and the Environment in Developing Countries: A Review of Opportunities and Developments. In: Berleur, J., Hercheui, M., Hilty, L.M. (eds.) HCC9/CIP 2010. IFIP AICT, vol. 328, pp. 236-247. Springer, Heidelberg (2010)

18. Bunse, K., Vodicka, M.: Managing Energy Efficiency in Manufacturing Processes - Implementing Energy Performance in Production Information Technology Systems. In: Berleur, J., Hercheui, M., Hilty, L.M. (eds.) HCC9/CIP 2010. IFIP AICT, vol. 328, pp. 260 268. Springer, Heidelberg (2010)

19. Santana, F.S., Barberato, C., Saraiva, A.M.: A Reference Process to Design Information Systems for Sustainable Design based on LCA, PSS, Social and Economic Aspects. In: Berleur, J., Hercheui, M., Hilty, L.M. (eds.) HCC9/CIP 2010. IFIP AICT, vol. 328, pp. 269-280. Springer, Heidelberg (2010)

20. Möller, A., Rolf, A.: IT Support for Sustainable Development in Organizations. In: Berleur, J., Hercheui, M., Hilty, L.M. (eds.) HCC9/CIP 2010. IFIP AICT, vol. 328, pp. 281291. Springer, Heidelberg (2010)

21. Dompke, M., von Geibler, J., Göhring, W., Herget, M., Hilty, L.M., Isenmann, R., Kuhndt, M., Naumann, S., Quack, D., Seifert, E.K.: Memorandum Nachhaltige Informationsgesellschaft. Fraunhofer IRB, Stuttgart (2004)

22. Göhring, W.: The Memorandum Sustainable Information Society. In: Proceedings 18th International Conference Informatics for Environmental Protection, EnviroInfo 2004, Geneva (2004), http: / /www.wolf-goehring . de/ OverMemoSIS . pdf 
23. Isenmann, R.: Sustainable Information Society. In: Quingley, M. (ed.) Encyclopedia of Information Ethics, pp. 622-630. IGI Global, Hershey (2008)

24. Streicher-Porte, M., Marthaler, C., Böni, H., Schluep, M., Camacho, A., Hilty, L.M.: One laptop per child, local refurbishment or overseas donations? Sustainability assessment of computer supply scenarios for schools in Colombia. Journal of Environmental Management 90(11), 3498-3511 (2009)

25. Dobson, J., Duncombe, R., Nicholson, B.: Utilising the Internet to improve peasant artisan incomes: Evidence from Mexico. In: Berleur, J., Hercheui, M., Hilty, L.M. (eds.) HCC9/CIP 2010. IFIP AICT, vol. 328, pp. 292-309. Springer, Heidelberg (2010) 